\title{
Raw Materials and International Relations
}

\author{
Published in: \\ S+F. Sicherheit und Frieden. Security and Peace, Thematic Focus: Economy, \\ Politics and Peace, 3/2017, pp 129 - 133. DOI: 10.5771/0175-274X-2017-3-129
}

Raimund Bleischwitz and Rüya Perincek

\begin{abstract}
This paper examines the role of raw materials in international relations, analysing areas of cooperation and conflict. It provides an overview of the changing global geopolitical landscape with the rise of the BRICs and the growing demand and competition over access. It then offers an analysis of emerging new scarcities and challenges linked to the resource nexus, making a case for the inclusion of a natural resource use perspective into global climate agreements and sustainable development goals. The paper presents examples of existing partnerships and initiatives, and concludes by arguing for a more coordinated and effective international resource governance. We also give an outlook on future challenges and some recommendations for international policy and academic research.
\end{abstract}

Keywords: raw materials, energy, water, food, resource nexus

Stichwörter: Rohstoffe, Energie, Wasser, Nahrungsmittel, Ressourcennexus

\section{Introduction}

Raw materials are the "skeleton" of economies, contributing to economic growth, innovation and competitiveness (Ali et al. 2017; Graedel et al. 2013). Yet, their deposits are distributed unevenly across the world. Besides sufficient amounts and quality, a whole range of other factors determine whether raw materials can be extracted and processed, such as access to transport infrastructure, land, energy and water resources, but also local community acceptance ensured through a regulatory and political approval process ('social license to operate'). A region's general political stability is another factor. Investors for such long-term assets usually do not go where there is violent conflict. Yet, raw materials have been fuelling conflicts as well as given incentives to cooperate. 
The race for resources has been accelerating over the last decades, not only for raw materials but also for land, water, and energy. It is imperative for international relations to understand this interconnectedness, as one material resource needs others to be produced. It has been described as the "resource nexus" (Andrews-Speed et al. 2014, Bleischwitz 2015), with underlying drivers of population growth, growing middle class and urbanisation.

This paper analyses the role of raw materials in international relations, looking into existing cooperation and conflicts. It starts by outlining the global geopolitical landscape in the context of raw materials and international environmental agreements. It then provides an overview of new scarcities and challenges arising from the resource nexus followed by a discussion of existing areas of cooperation and initiatives. Finally, the paper concludes by identifying the main areas of future challenges and by drawing concrete recommendations for international policy and academic research.

\section{The Global Context}

\subsection{Geopolitics: The rise of the BRICs and competition over access to raw materials}

Geopolitics describes the relation between politics and territory, whether on local or international scale, helping foreign policy analysis to understand, explain and potentially predict international political behaviour primarily in terms of geographical variables. These include: geographic location, size, climate, demography and natural resources available in the territory as well as the level of technological development. Geopolitics has its origins in colonialism based on political aspirations to control new territories and exploit a wide range of new resources. Such earlier approaches have been challenged by more recent research moving away from a state-centric approach toward a contemporary focus on globalization taking into account global economic, political and social connections shaping international relations. The recent strand strives to account for a new and complex reality, combining traditional and new dimensions of geopolitics to offer a multidimensional view of power relations. The importance of geography is complemented by the combination of hard or soft power tools that states can employ to project power. The recent evolution of geopolitics shows that the international context in which countries act from a historical and geographic 
perspective matters, and that domestic and foreign spheres are interlinked. The domestic needs determine the foreign resource policy, and classical colonialism has been replaced with a more complex mix of policy tools used to secure access to resources.

With the economic rise of the BRIC countries, there has been emerging competition over resources. In 2010, five main emerging economies consumed 54 per cent of global metals, of which only six per cent stemmed from Europe and North Africa and of which 76 per cent were extracted in four countries, namely Australia, China, India and Brazil (Schaffartzik et al. 2016). China is one of the major producers and consumers, with a unique resource strategy exemplifying the conditioning of foreign resource policy by domestic needs (Moyo, 2014). With regard to many single raw materials, China has become a "Monopsonist", the single important buyer setting the price - especially for coal and copper. The country has recently bought a mountain full of copper in Peru to secure supply for the next 30 to 40 years.

The global demand for metals and minerals has increased with the rise of these new emerging economies. Although they are rich in metals and minerals, they increasingly export less raw materials as domestic demand grows. These potential exporters have been through a great transformation - and will continue to do so. China, a raw materials exporter, has become a net importer. Hence, advanced European economies compete with countries such as China over access. The fact that resource extraction and production is concentrated in some thirty countries, labelled by a Chatham House report as R-30 (Lee et al. 2012), poses challenges for international relations.

Raw materials are a crucial element of the European transition to a low carbon economy. The European Union's desire to reach a low carbon economy is motivated by environmental interests such as the reduction of greenhouse gases and mitigation of climate change effects as well as geopolitical interests, namely security of access and supply. Rare earth elements in particular constitute an essential part of a green economy as neodymium, for instance, which is essential for the production of magnets used in wind turbines or hybrid cars. Praseodymium, another rare earth element, is needed for the manufacturing of strong metals for aircraft engines. In fact, 80 to 90 per cent of rare earth elements are not produced in Europe, but China. It is therefore imperative to engage with China and other important suppliers in open trade partnerships. 
Hilpert and Mildner (2013) demonstrate the fragmentation of global resource governance and absence of coordination based on a comparative analysis of raw materials strategies of the G20 countries. They identify the following barriers: first, there are diverging priorities and concerns. In light of rising prices and growing scarcities, import-dependent industrial countries, e.g. France, Germany, Italy and Japan are primarily concerned with security of supply and industrial competitiveness. Germany has become the number one secondary materials exporter in Europe, which is a consequence of resource efficiency and recycling policies. Therefore, innovative early industrialisers might become in the near future the world's leading producers of recycled materials with lower energy and material requirements, as recycling rates are growing and anthropogenic stocks in landfill, durable products and buildings become of strategic importance in terms of raw materials independence (Schaffartzik et al. 2016). Furthermore, Germany has concluded bilateral agreements with countries such as Chile, Peru, Mongolia or Kazakhstan to secure access and supply complementary to the other tools in the domestic policy mix. China, despite its large domestic mining sector fears supply shortages threatening its own development and industrialisation. Hence, China has established "resource-for-infrastructure" swaps with third countries, which include food and uranium swaps with Canada, Brazil or Kazakhstan (Moyo, 2012). Producer countries, e.g. Australia, Brazil, Canada, Russia and South Africa welcome rising prices and see them as a chance for prosperity and development - regardless of the environmental implications. Hilpert and Mildner (2013) also identify diverging views on the role of states and markets: while Anglo-Saxon countries believe in the effective allocation via free markets, European and East Asian countries do not overlook market distortions and failures and tackle risks of disruptions in supply chains.

In conclusion, demand-side countries such as Germany or China try to keep close ties with resource-rich countries and engage in strategies to curb demand. China invests in infrastructure in return for access and pays high amounts for large volumes of valuable assets, whereas countries such as Germany establish partnerships in exchange for knowledge and technical assistance coupled with resource efficiency and recycling policies to reduce dependence. While the two and a number of other countries such as Japan and South Korea are clearly resource-dependent, it would be an illusion to believe that resource-rich countries are resource-independent. All countries need to import a range of resources, goods and services to uphold current living standards and meet domestic demand, be it speciality metals for electronics and IT, or food with its inherent water footprints. Therefore, current debates on 
"energy abundance" - as discussed in the USA due to the large supply of unconventional fuels - need to be seen in a wider context of remaining interdependencies.

\subsection{International environmental policies: The Paris Agreement, SDGs and the need to include resources}

The 2015 Paris Agreement on climate change has been a strong signal sent by 196 states to become serious about reducing greenhouse gas emissions and shifting to low carbon energy systems worldwide. It reflects shifting responsibilities towards nationally determined contributions although current country pledges are still not enough to meet the goal of keeping global temperature rise "well below $2{ }^{\circ} \mathrm{C}$ ". More needs to be done. The launch of the Sustainable Development Goals (SDG), a set of universal goals trying to address the urgent environmental, political and economic challenges of our time, was in parallel to the Paris Agreement and can be seen as yet another promising milestone.

Important from a raw materials perspective is the insight that their environmental goals have implications for resources. It is evident that climate action will impose constraints on the future use of fossil fuels. Many of the alternative energies and the new SDGs however will lead to an increase in material demand; for instance:

- Goal 2 to end hunger implies, inter alia increasing demand for mineral fertilizers and water,

- Goal 6 on the sustainable management of water and sanitation implies investments in water supply and a water distribution infrastructure, i.e. increasing demand for materials,

- Goal 7 related to energy is likely to imply increasing demand for bio-energy and renewable energy, which again implies more demand for land, biomass, water, and materials.

- Goal 9 to build resilient infrastructure will require more construction materials, metals, and other materials.

In a balanced view, the SDGs also endorse the sustainable production and consumption agenda, call for the global increases in resource efficiency, establishment of sustainable and resource-efficient infrastructures by 2030 (goal 9) and sustainable management and efficient 
use of all resources by 2030 (goal 12). Thus, given the broad range they cover, overall policy coherence is crucial. However, the balance between such expected demand increases and other goals is not yet sufficiently addressed. For instance, key terms such as sustainable management or the efficient use of all resources are not well defined and leave space for different implementation pathways. Thus, research will be pivotal in addressing the interlinkages and trade-offs in the implementation of the SDGs, which needs to be done from an international relations perspective.

In the meantime, "new scarcities" have emerged: The question of how much oil can be supplied, has turned into how much oil should be supplied given constraints such as climate change, health, or air quality. The complexity of nature and its interactions with societies is currently often discussed under the narrative of the water - energy - food nexus. ${ }^{1}$ This nexus approach refers to interlinkages among the use of natural resources at different scales, illustrated by water needed for both energy and food production (Hoff 2011, Andrews-Speed et al. 2014). It can be defined as the set of context-specific critical interlinkages between two or more natural resources used as inputs into socio-economic systems. The aim of the resource nexus approach is to look at critical connections in a more integrated manner, in particular at minimum supply conditions, threshold values, synergies and tradeoffs.

The nexus with materials is characterised by declining ore grades and the increasing intensity of water and energy use in mineral extraction processes (Giurco et al. 2014; Meinert at al 2016). While such 'new scarcity' underlines the vulnerability of many extractive industries and subsequent manufacturing processes, it might also inform mineral resource development and/or possible guidelines for planetary mineral consumption, as suggested by Nickless (2016) based on recent environmental research findings about a safe operating space (Rockström et al. 2009; Steffen et al. 2015). The resource nexus has become more pressing in recent years because volatile commodity prices transmit turbulences from local to global markets faster than ever before. Recent evidence on the dangerous conjunction of high food prices, water and social tensions were witnessed during the Arab uprisings in 2011. Sternberg (2012) points to the drought that occurred in Northern China as a global trigger for higher food prices; with Egypt having been the largest importer of wheat worldwide at that time, higher food prices have contributed to social unrest.

\footnotetext{
${ }^{1}$ See also the work of the UK nexus network at: http://www.thenexusnetwork.org; the Future Earth Knowledge Action Network on the nexus at: http://futureearth.org/future-earth-water-energy-food-nexus; or one of the origins: http://www.water-energy-food.org
} 
However, the relationship between local water and food shortages, resource constraints, socio-economic struggle and political unrest is a complicated one. In recent years, concern about the intersection of climate change and security have grown rapidly. Climate change is increasingly seen as a stress multiplier for both traditional national and inter-state security and a much broader human security agenda. As the IPCC "Human Security" chapter (Adger et al. 2014) points out, there is a myriad of, often complex, causal pathways through which climate change connects to national, interstate and human security concerns. Such threat multipliers may manifest in local communities or within a region of a single country, or spill over borders and involve whole societies. This is not a simple claim that resources or climate change cause conflict on their own. Rather, such factors may increase the risks of violence in particular contexts. It also intersects with long-standing social and political conflicts, some of which are or could become violent. Fragile countries and regions are likely to become more vulnerable, but other regions including the industrialised countries will have to cope with the indirect impacts too. Adaptive capacities need to be developed for the directly affected regions and others more indirectly affected.

In conclusion, there are manifold security implications of new scarcities, the nexus and climate change that are likely to play into international relations and geopolitics. Regional security implications and mass migration are potentially severe and will not leave Europe unaffected. The Paris Agreement on climate change as well as the SDGs offer some promising platforms for strategies, yet they need to consider the implications for global resource use and achieve coherence.

\section{Partnerships and Initiatives}

There are a wide range of policy instruments and initiatives in the context of raw materials. Some focus on ensuring transparency to fight corruption and patronage in resource-rich countries to secure the long-term benefit of revenues for the broader population. Others include bilateral or multilateral cooperation in the field of technical expertise and knowledge sharing to make use of opportunities of applying green technologies in extraction processes and at the early stages of the supply chain. The section below introduces and discusses a couple of examples. 


\subsection{The Extractive Industries Transparency Initiative (EITI)}

The economic and political relation among raw materials exporting and importing countries is mostly influenced by the extraction-based growth agenda. Past experience with the "resource curse", i.e. failed attempts of harnessing the benefits of commodity cycles in developing countries, has led to a number of transparency initiatives to fight corruption and related conflicts through good governance. The participation in the EITI has become a conditionality for trade and aid relations between developing countries rich in resources and the European Union countries or the United States. The EITI as a voluntary code has proven to be a powerful instrument (Collier, 2008). The basic rationale is informational, suggesting global standards to promote the open and accountable management of extractive resources. It is a source of good pressure revealing those who are willing to comply with the EITI standards and those who are not - creating strong incentives for governments not to be seen in the latter category. After the launch of the EITI, the United States (Dodd-Frank Act) and the European Union (EU Accounting and Transparency Directive) have introduced legislation supporting the voluntary initiative through "hard law" - making it a requirement for listed companies to disclose their payments for exploration and extraction in resource-rich countries as well as the use of conflict minerals. However, the future of this initiative might be uncertain, as the current U.S. President Donald Trump wanted to repeal the Dodd-Frank Act. Rolling it back would potentially weaken efforts such as EITI and have international knock-on effects on other countries in their support for disclosure. In turn, the disclosure of payments and transparency on public investments make up for a great contribution to economic development and political stability. Given the vulnerabilities of resource-rich developing countries (Bleischwitz et al. 2014), these global initiatives need to take environmental aspects of extraction into consideration as part of the broader "good governance" agenda. Local food and water supply constraints coupled with climate change effects contribute not only to supply disruptions but also conflicts. The inclusion of environmental standards would be complementary to existing technical cooperation for the sustainable use of resources and consistent with the aim to promote "good resource governance". 


\subsection{Bilateral cooperation: The case of Chile}

Chile is the world's most important copper exporter, yet energy poor and exposed to climate change effects such as draughts and water shortages. It is an open and export-oriented economy with 24 free trade agreements with over 60 countries - 17 of which contain environmental provisions (OECD, 2016). The trade agreements with Canada, the European Union and the United States include strong environmental provisions. In return for economic cooperation, Chile has accepted to promote high environmental standards, the strict enforcement of environmental laws and reforms in the country's environmental legislation. Based on positive technical cooperation, for instance with the US on the monitoring and protection of glaciers or Germany on the promotion of renewable energy, the country has actively promoted the inclusion of environmental provisions in its more recent trade agreements with dedicated articles or even chapters. These resulted in a number of environmental cooperation projects. Under the Chile-U.S. agreement alone, almost 80 environmental cooperation activities have been carried out since 2005 (OECD, 2016). According to the Organisation for Economic Co-operation and Developments (OECD) Environmental Performance Review, Chilean officials acknowledge the trade-related instruments contribution to the strengthening of the country's institutional capacity and environmental management more generally. The European Union is another trading partner of Chile's, which has conducted a sustainability assessment of the Chile-EU Association Agreement. In the two ex-post analyses, the EU found that the association agreement has encouraged agricultural producers to adopt higher social and environmental standards. The second state identified improvements in environmental standards and management practices concluding that overall, the impact of the association has helped to strive for higher environmental and social standards contributing to peace and stability in the country.

Chile is a good practice example of an emerging resource-based economy, which uses its resources sector as an anchor to attract investments but also to bring in technical expertise and eco-innovative technology into the country within the broader context of green growth. In 2009, the country launched a call for the installation of International Centres of Excellence (ICE). These are joint research and development institutions (R\&D) bringing together innovative international players and local partners. Their aim is to provide easy access to international investors, skills and technology, while promoting a local environment for innovation, building local skills and strengthening links between research and Chilean 
businesses. By early 2015, 13 ICEs had been established, including for activities related to green growth. The Centre for Solar Energy Technologies, for example, is jointly operated by the German Fraunhofer Institute for Solar Energy Systems and the Catholic University of Santiago conducting applied research on solar electricity generation, solar heat for industrial use and solar water treatment (OECD, 2016).

German organisations have been active in the country's resource sector since 1990s. In 2012, the German Chamber of Foreign Trade has established a competence centre for the efficient extraction and use of raw materials. The German Federal Agency for Sustainable Development, named GIZ (Gesellschaft für Internationale Zusammenarbeit), is an active international partner collaborating with the German Ministry of Environment and Chilean Ministry of Energy in supporting large-scale photovoltaic projects in Chile within the 4e Program - Renewable Energy and Energy Efficiency Program in Chile commissioned by German Federal Ministry for Environment with the objective to reduce greenhouse gases (GHG) through renewable energy and energy efficiency. GIZ supported Chile technically in developing a strategy for grid-connected renewable energy (2009-2013) and long-term energy planning. Together with the Ministry of Energy, a technical and economic assessment of solar applications in the mining sector was conducted. The agency contributed actively to knowledge creation by, for instance, supporting a study of existing large photovoltaic plant in Chile, which revealed existing challenges and opportunities in mainstreaming renewables in the mining sector informing policy makers, investors and R\&D institutions. Such an approach helps closing knowledge gaps on opportunities and potentials of eco-innovation, i.e. increasing the share of clean energy and reducing GHG emissions from raw material extraction. Finally, Chile being a water-poor country has increased significantly the use of renewable energy at its mine sites to desalinate water for the extraction, setting the example of applying green technologies in extraction processes.

\subsection{The Initiative for Resource Efficiency and Climate Protection (by the GIZ)}

Many scholars (Moyo, 2012; Hilpert and Mildner, 2013; Bleischwitz, 2014) have criticised the absence of an international discussion on natural resources, particularly at G20 level where financial regulation and other issues are being discussed. The GIZ works on a project, which is surely a step to the right direction addressing the issue of resource efficiency and 
climate protection at G20 level. The GIZ supports the German Federal Ministry for the Environment in international cooperation activities on resource efficiency and climate protection. The Initiative for Resource Efficiency and Climate Protection is tailored for emerging countries, in particular the G20, with significant industrial growth rates and associated resource consumption and GHG emissions. It aims to exchange knowledge and provide technical support to key public and private stakeholders in the development and implementation of integrated approaches to increase resource efficiency and thus to improve climate protection. In close coordination with the German Federal Ministry for the Environment, the GIZ facilitates the establishment of a dialogue process on resource efficiency within the G20 framework, also with regard to meeting the climate protection commitments and the successful implementation of the Sustainable Development Goals. They elaborate expert opinions, assessments and comments for the Federal Ministry on international processes in the area of resource efficiency and climate protection. The GIZ facilitates networking activities among relevant professional actors and provides adequate control of cooperation with selected project partners and subcontractors. Moreover, it coordinates the preparation, implementation and evaluation of training, dialogue and awareness-raising activities of the project. It gives advice to partner countries on the more efficient use of raw materials and natural resources building upon the German experience as well as the on the identification and development of greenhouse gas reduction potentials, taking into account national climate protection targets as well as appropriate promotion instruments and incentives. Finally, the organisation creates concept papers and task descriptions for studies in order to identify potentials for resource efficiency and climate protection tailored for each particular country context. This project has the potential to help reducing the spatial disconnect between supply-side and demand side countries in addressing negative environmental implications resulting from extraction. The results, however, are yet to be seen.

\section{Conclusions and Perspectives}

This article underlines the important role of raw materials in international relations and calls for a more coordinated and effective international resource governance. It does so following our analysis of the global geopolitical landscape with the rise of the BRICs and the growing demand and competition over access to resources. Another reason to establish a 
comprehensive resource policy in international relations stems from the need to access resources for low carbon policies and challenges linked to the resource nexus. There is also a strong case for including a natural resource use perspective into all climate agreements and the implementation of sustainable development goals.

The article also discusses selected existing partnerships and initiatives that seem to move in such direction, such as the EITI and other attempts for disclosing relevant information. The Chilean example shows opportunities of applying green technologies in extraction processes and early stages of the supply chain, including renewable energies. Such initiatives could and should be extended by focusing also on circular economy options, both domestically as well as in international relations. Accordingly, the paper stresses the importance of multi-level stakeholder partnerships highlighting one existing initiative of the German GIZ. Extending such partnership towards the G20 and other selected key countries should help establishing a platform for a global discourse on resource governance.

We conclude by pointing at a recent global green shift (Mathews 2017): while the US administration under President Trump begins to withdraw from important international partnerships such as the Paris Agreement on climate change, China indicates its readiness and political will to step up. Long-standing European beliefs in an international liberal order and trust in a transatlantic partnership are at stake. A new position for Europe and a role for Germany will need careful thoughts. Our perspective of an international resource governance with potential support from business and for sustainable development should be vital in such broader strategic thoughts.

\section{Bibliography}

Adger, W. N., et al. (2014). Human security. In Climate Change 2014. Impacts, Adaptation, and Vulnerability. Part A. Global and Sectoral Aspects. Contribution of Working Group II to the Fifth Assessment Report of the Intergovernmental Panel on Climate Change (pp. 755-791). New York. USA: Cambridge University Press.

Ali SH et al. (2017). Mineral supply for sustainable development requires resource governance. Nature, March 2017. doi:10.1038/nature21359.

Andrews-Speed et al. (2014). Want, Waste or War? The Global Resource Nexus and the Struggle for Land, Energy, Food, Water and Minerals. Routledge Publisher.

Berry, P. (2010). Farmers Meet for Murray Water Talks. The Sydney Morning Herald.

Bleischwitz, R., Johnson, C.M., Dozler, M.G. (2014). Re-Assessing resource dependency and criticality. Linking future food and water stress with global resource supply vulnerabilities for foresight analysis. European Journal of Futures Research. Vol. 2(1). 34. DOI 10.1007/s40309-013-0034-1. 
Bleischwitz, R. (2014). Transparency in the Extractive Industries. Time to Ask for More. Global Environmental Politics. Vol. 14(4). DOI:10.1162/GLEP_e_00254.

Bleischwitz, R. (2015). Der Ressourcen-Nexus als Frühwarnsystem für zukünftige zwischenstaatliche Konflikte. in: Zeitschrift für Außen- und Sicherheitspolitik (ZfAS) 8. 2015. (pp. 9-22). DOI 10.1007/s12399-0140435-7.

Bringezu, S. and Bleischwitz, R. (Eds). (2009). Sustainable Resource Management. Global Trends, Visions and Policies. Greenleaf.

Collier, P. (2008). The Bottom Billion. Regulation of Natural Resources. Oxford University Press.

Moyo, D. (2012). Winner Take All. China's Race for Resources and What It Means for the World. Basic Books.

Giurco, D. et al. (2014). Responsible mineral and energy futures. views at the nexus. Journal of Cleaner Production. $84 . \quad$ (pp. 322-338). Available at: http://www.sciencedirect.com/science/article/pii/S0959652614006805.

Graedel, T.E., Harper, E.M., Nassar, N.T., Reck, B.K. (2013). On the materials basis of modern society. PNAS 201312752.

Hilpert, H.G. and Mildner S.A. (Eds.). (2013). Fragmentation or Cooperation in Global Resource Governance? A Comparative Analysis of the Raw Materials Strategies of the G20. SWP Research Paper 2013/RP 01, March 2013.

Hoff, H. (2011). Understanding the Nexus. Background Paper for the Bonn2011 Conference: The Water, Energy and Food Security Nexus. Stockholm Environment Institute, Stockholm.

Lee B, et al. (2012). Resources futures. Chatham House. London.

Mathews, John (2017). Global Green Shift. When Ceres Meets Gaia. Anthem Press.

Meinert, L.D., Robinson, G.R., Nassar, N.T. (2016). Mineral Resources. Reserves, Peak Production and the Future. Resources 5. (pp. 14). doi:10.3390/resources5010014.

Nickless, E. (2016). Resourcing Future Generations. A global effort to meet the world's future needs head-on. European Geologist 42. (pp. 46-50).

OECD (2016). Environmental Performance Review Chile.

Rockström, J. et al. (2009). A safe operating space for humanity. Nature 461. (pp. 472-475).

Schaffartzik, A. et al. (2016). Global patterns of metal extractivism. 1950-2010. Providing the bones for the industrial society's skeleton. Ecological Economics 122 (2016). (pp. 101-110).

Sternberg, T. (2012). Chinese drought, bread and the Arab spring. Appl Geogr 34. (pp. 519-524).

Steffen, W. et al. (2015). Planetary boundaries. Guiding human development on a changing planet. Science (80). (pp. 347). 